\title{
Pilot clinical trial of an asymmetrical balloon in the treatment of epistaxis in adult patients*
}

Christian Debry ${ }^{1,2}$, Léa Fath ${ }^{1,2}$, Laura Nakhleh', Guillaume Trau', Idir Djennaoui', Pierre Mahaudeau', Naif Bawazeer', Pauline Paris', Saït Ciftci 1,2

'Hôpitaux Universitaires de Strasbourg, Service de chirurgie ORL et cervico-faciale, Hôpital Hautepierre, Strasbourg, France INSERM Unité 1121, 11 Rue Humann, Etage 7, 67000 Strasbourg, France
Rhinology Online, Vol 3: 89 - 99, 2020

http://doi.org/10.4193/RHINOL/20.039

*Received for publication:

May 4, 2020

Accepted: June 4, 2020

Published: June 11, 2020

\begin{abstract}
Objective: To assess safety and efficacy of an asymmetrical balloon in the treatment of epistaxis in adult patients ( $\geq 18$ years) managed in an emergency setting.
\end{abstract}

Methodology: Pilot, open label, monocenter, prospective, interventional non comparative study in adult patients. The patients were hospitalized for 48h, timepoint at which the device was removed. Primary endpoints were the assessment of bleeding arrest and pain score evaluated on a Visual Analogic Scale. Secondary endpoints were the nature and number of adverse events reported and patient quality of life evaluated with the RhinoQoL questionnaire.

Results: Ten patients were included, and nine were treated. In Intent to Treat (ITT), bleeding was stopped upon positioning in 9/10 patients. Efficacy was maintained in 8/10 patients during treatment. Pain was moderate at insertion, inflation and during treatment and mild upon and post-removal. Minor bleeding recurrence occurred in two patients during the post-treatment period. The reported adverse events considered device-related were consistent with the ones observed with other intranasal devices. The mean and median RhinoQoL impact scores tend to decrease upon the different control visits.

Conclusion: This pilot study provides promising preliminary safety and efficacy data for CAVI-T ${ }^{\mathrm{TM}}$ in the management of epistaxis in an emergency setting.

Key words: balloon, epistaxis, nasal packing, nasal tampon, nose bleeding.

\section{Introduction}

Intranasal bleeding (epistaxis) is the most frequent Ear, Nose and Throat (ENT) emergency. It impacts $60 \%$ of the population at least once during their lifetime ${ }^{(1,2)}$. In Emergency Departments specializing in ENT, it represents more than $11.5 \%$ of admissions and a quarter of hospitalizations ${ }^{(3)}$. Moreover, its frequency increases, mainly because of the aging of the population and also because of the growing use of antiplatelet agents and, more recently, new oral anticoagulants (NACO) ${ }^{(4)}$. Thus, the management of these patients represents a major challenge for ENTs and emergency physicians.

In epistaxis, the therapeutic strategy depends on patient risk factors, etiology and monitoring requirement. Once hemodynamic factors are controlled (blood pressure, transfusion, oxygen), the goal is to rapidly control hemorrhage.

The current approach is, for patients not responding to bi-digital compression, to perform cauterization or anterior packing with nasal tampons or ribbon gauze as first line therapy.

Although cauterization may present significant advantages as a first line therapy ${ }^{(5)}$, bleeding site is not always clearly identifiable in the emergency setting. Pending ENT physicians would be readily available to perform cauterization in the emergency Department, this may be an interesting first line treatment modality. Tamponade with anterior and posterior epistaxis catheters may be used in case of failure of the anterior nasal packing or 


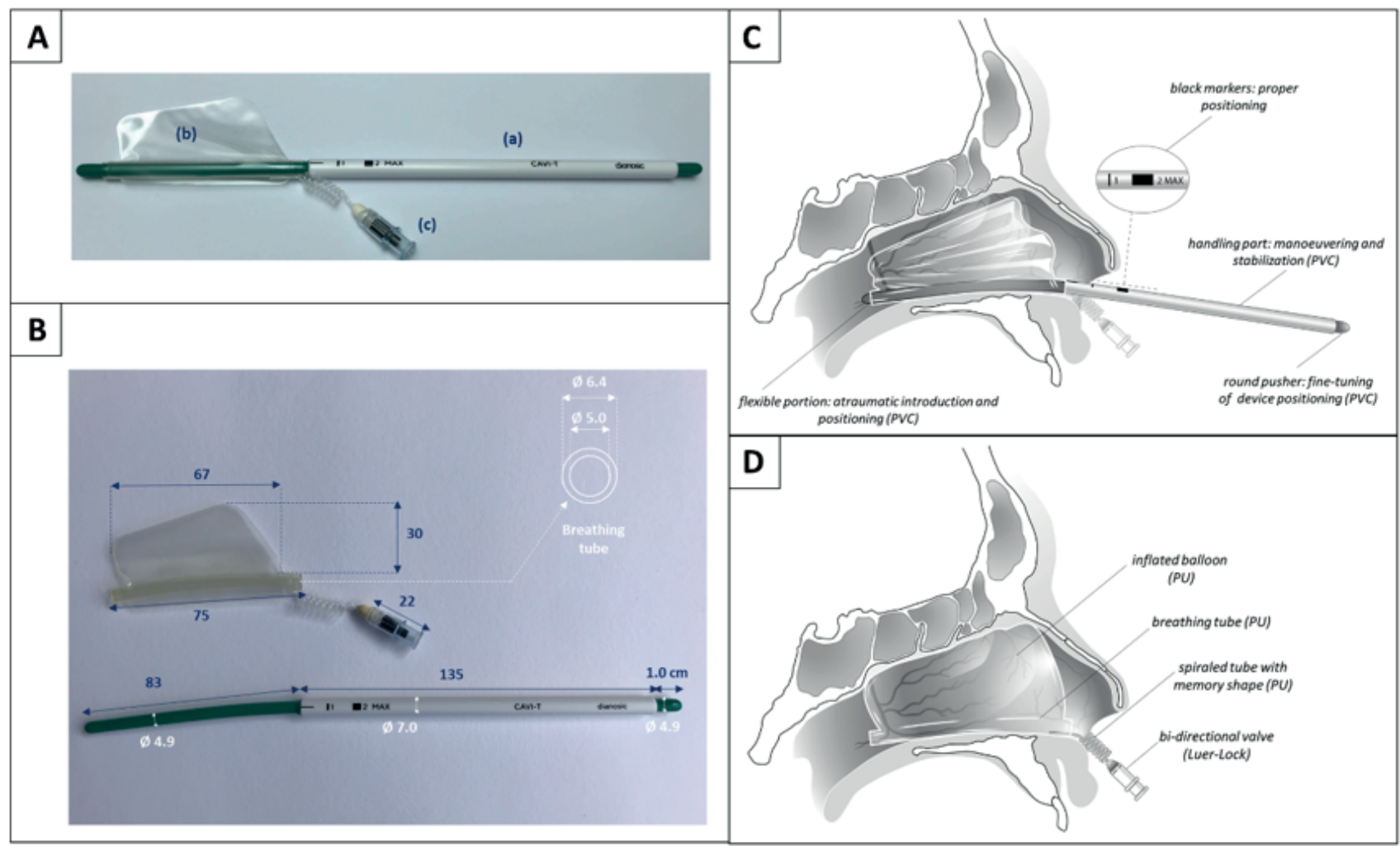

Figure 1. A. Components of the CAVI-T'M device - (a) deployment guide, (b) balloon, (c) bi-directional valve ; B. Details of the dimensions of the different components ; C. Sagittal section showing the insertion of the non-inflated balloon with the deployment guide; D. Sagittal section showing the positioning of the inflated balloon in the nasal cavity.

recurrence of epistaxis. The third line treatment to consider, if bleeding is not controlled, is ligation of the sphenopalatine artery under general anesthesia or embolization in interventional radiology ${ }^{(6)}$.

The major drawback of nasal tampons is linked to the pain, often severe, and to the discomfort that it provokes upon placement, during the 24 to 72 -hour compression phase, as well as upon removal. In a study by Kindler et al., patients remember years after the pain and the discomfort that they experienced ${ }^{(7)}$. Moreover, a prolonged non-physiologic compression exerted on the tissues with balloon catheters can promote necrosis of the nasal septum with a potential perforation or even the necrosis of the alar cartilage or the columella with possible esthetic sequelae $^{(8)}$.

Also, in France, hospitalizations (up to 48 hours) ensuring optimal patient monitoring as well as hospital revisits are not rare with these treatments (especially with balloon catheters) ${ }^{(9)}$. It is worth noting that practice may vary, and it appears that in the United States, patients may not be hospitalized, especially in case of unilateral bleeding.

A study from Coey et al. suggests that fibrin tissue adhesive may be effective in controlling bleeding ${ }^{(10)}$. Although it might present minor advantages over nasal packing in a surgical setting, the cost of such treatment makes it currently unlikely that they'd been used broadly in patients presenting to the emergency department with an epistaxis.

Therefore, the need for alternative treatment options acting by compression remains pregnant.

In order to overcome these challenges and lessen patient morbidity while preserving at least a similar level of success, an asymmetrical balloon (CAVI-T ${ }^{\mathrm{TM}}$ ) has been developed. Unlike other balloons that do not conform to the nasal cavity, CAVI-T'M has been designed to mimic its shape. Its contour is expected to optimize its conformation to the anatomy (Additional file 1) while offering a low-pressure, physiological mucosal compression option to control anterior and/or posterior bleeding, thus potentially leading to an improved benefit-risk ratio and patient quality of life.

This pilot study was primarily designed to provide first data regarding the safety and performance of CAVI-T'M in the management of epistaxis in an emergency setting. The secondary objectives were to: a) assess general complications (pain, infections, synechiae and granulomas, necrosis, septal perforation) potentially caused by the device and b) evaluate patient quality of life upon device introduction, inflation and removal. 

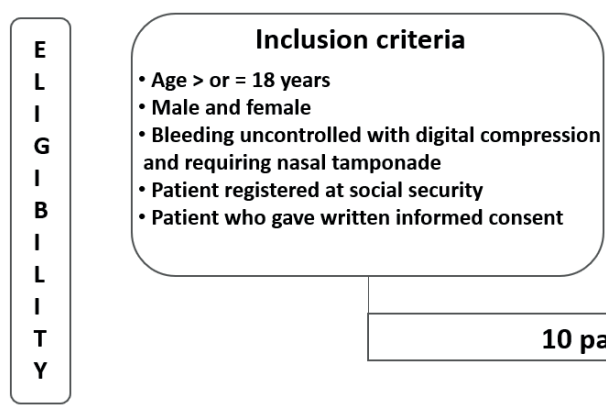

Exclusion criteria

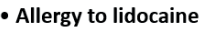

Primary endpoints

- Device performance: absence of bleeding following balloon inflation during first 48 hours and absence of rebleeding following removal at $\mathbf{4 8}$ hours and $\mathbf{9}$ days following removal

- Device safety: pain score on a VAS (Visual Analogic Scale)

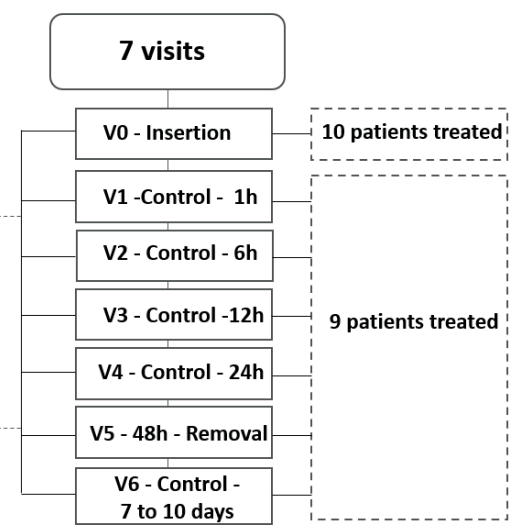

Figure 2. Description of the design of the study.

\section{Materials and Methods}

\section{Device description}

CAVI-T ${ }^{\mathrm{TM}}$ is an asymmetrical intranasal balloon catheter indicated in adults ( $\geq 18$ years) to control intranasal bleeding by compression upon intranasal structures. The sterile balloon is designed to conform to the intranasal anatomy upon inflation to stop spontaneous or perioperative bleeding and can stay in place for a maximum of 3 days before removal. It is equipped with a breathing channel for increased patient comfort (Figure 1). CAVI-T'M is CE marked since February 2020. It is composed of a balloon (polyurethane), a deployment guide (polyvinyl chloride) and a bidirectional valve connectable with a Luer Lock syringe for inflation/deflation (Figure 1, A-B).

\section{Study design}

The study design is detailed in Figure 2.

This study is the first pilot, open label, monocentric, prospective, interventional non-comparative study undertaken with CAVI-T ${ }^{\mathrm{TM}}$. Ten adult patients were enrolled from March 2019 to July 2019 in the ENT Department of Strasbourg University Hospital. Research was conducted in accordance with the principles of the Declaration of Helsinki, Good Clinical Practices, ISO 14155, the protocol and current regulation. In compliance with Article L1121-4 of the French Public Health Code, the sponsor received approval of the Ethics Committee and the Competent Authority before initiating the research.

In compliance with the Ethics Committee and Competent Authorities requirements, investigators provided all necessary information to the patient regarding the study. All patients provided written informed consent prior to their enrollment.
At inclusion visit (V0), once patient consent was signed, the nose was sprayed with intranasal lidocaine naphazoline $5 \%$ and the device was positioned. The balloon was inflated with air with a maximal recommended quantity of $25 \mathrm{~mL}$ of air. Patients current treatments were resumed, and any anticoagulant treatments discontinued, replaced or pursued according to their clinical circumstances. No prophylactic antibiotics were systematically prescribed.

Control visits were performed during treatment $(1 \mathrm{~h}, 6 \mathrm{~h}, 12 \mathrm{~h}$, $24 \mathrm{~h}$ ), at removal visit (48h) and 7 to 10 days after removal. Information gathered and examinations performed at each visit are detailed in Additional file 2.

Adjustment of the volume of air within the balloon (reinflation or deflation) was possible directly after positioning and at each control visit by injecting or removing a certain volume of air thanks to the connection of a Luer Lock syringe to the bidirectional valve of the device.

The patient consent withdrawal, a poor safety or efficacy of the device, the loss of vision or death were the criteria defined to prematurely terminate treatment with CAVI-T ${ }^{\mathrm{TM}}$. The study was registered on ClinicalTrials.gov under identifier NCT03912051.

\section{Concomitant treatments}

There was no specific concomitant treatment (analgesics, anticoagulants, etc.) contraindication. Topical lidocaine (5\%) was used as a local anesthetic prior to product placement. In the event that alternative solutions were required to replace CAVI$\mathrm{T}^{\mathrm{TM}}$ or escalate treatment, various therapeutic options could be used: cauterization, gauze / tampons (resorbable or not), traditional epistaxis catheters, ligation or embolization. 
Table 1. Demographics and baseline characteristics.

\begin{tabular}{|lc|}
\hline \multicolumn{1}{|c}{ Demographics } & 10 \\
\hline $\mathrm{n}$ & $72.3[9.9]$ \\
\hline Age, mean [SD] & 5 \\
\hline Male & \\
\hline Medical history & 10 \\
\hline Cardiology & 1 \\
\hline Diabetes & 1 \\
\hline Epilepsy & 2 \\
\hline Cancer & \\
\hline Anticoagulant therapy & 10 \\
\hline (non- epistaxis related) & \\
\hline Anticoagulant therapy & 4 \\
\hline Anticoagulant agent & 4 \\
\hline Antiplatelet agent & 1 \\
\hline Anticoagulant + antiplatelet agents & \\
\hline Epistaxis & 10 \\
\hline Unilateral & 0 \\
\hline Bilateral & 0 \\
\hline Missing & 3 \\
\hline Bleeding site & 3 \\
\hline Anterior & \\
\hline Posterior & \\
\hline Anterior / posterior & \\
\hline & \\
\hline
\end{tabular}

\section{Primary endpoints}

The primary efficacy endpoint of the study was the assessment of bleeding arrest upon CAVI-TM placement (V0), the absence of bleeding recurrence during the $48 \mathrm{~h}$ post balloon positioning ( $1 \mathrm{~h}, 6 \mathrm{~h}, 12 \mathrm{~h}, 24 \mathrm{~h}, 48 \mathrm{~h}$ ), and 7 to 10 days post removal (V6). The primary safety endpoint was pain evaluated by the VAS, ranging from 0 (no pain) to 10 (unbearable pain), at introduction and inflation of the balloon (V0), during treatment (1h, 6h, 12h, 24h), upon removal (48h) and 7 to 10 days post removal.

\section{Secondary endpoints}

Secondary safety endpoint was assessed by the nature and the number of adverse events identified at each planned control visit. Each adverse event was classified as a function of its severity and its direct relation to the medical device. The presence of any mucosal damage after balloon removal (necrosis, synechiae, granulomas) was assessed endoscopically by the investigator. The patient quality of life was evaluated with the RhinoQoL questionnaire validated in French ${ }^{(11)}$ at V0, 24h, $48 \mathrm{~h}$ and 7 to days post removal. Frequency (maximum score: 16) and impact (maximum score: 36 ) scores were determined by asking the patients how often they had the listed symptom or the listed problem because of their nasal symptoms on a 0 ("none of the time") to 4 scale ("all of the time"). Bothersomeness score (maximum score:
30) was assessed by evaluating how bothered the patients were by the listed symptom on a 0 ("not bothered at all") to 10 ("bothered a lot.") scale ${ }^{(11-13)}$.

\section{Hospitalization duration}

Per protocol, patients had to be hospitalized for a minimum of two days. Although patients might have been discharged earlier with CAVI-T ${ }^{\mathrm{TM}}$, they were not since it was the first time this device was used in human subjects. It was decided to align patient management on the "worst case" scenario in France i.e. double balloon catheters which often require a strict monitoring in hospital for up to 2 days. Investigators provided an estimate regarding what the length of stay could have been in case the same patients were managed outside of the context of the study.

\section{Statistical analysis}

Only descriptive statistical analyses were conducted. Results are provided in Intent to Treat (ITT).

\section{Results}

Baseline characteristics

The baseline characteristics are reported in Table 1.

\section{Primary endpoints}

Efficacy

\section{Product positioning (V0)}

The CAVI-T ${ }^{\mathrm{TM}}$ balloon was inflated on average [SD] with $15.9 \mathrm{~mL}$ [4.8] of air (median $=15.0 \mathrm{~mL}$ ) for a maximum recommended of $25 \mathrm{~mL}$. The volume of air was directly adjusted for four patients (4/10): the balloon was slightly deflated for two patients $(2.5 \mathrm{~mL}$ [0.7]), moderately deflated for one patient $(1 / 10)(10 \mathrm{~mL})$ and slightly reinflated for one patient (1/10) (2mL) (Additional file 3). Bleeding was stopped in 9/10 patients. One patient had a major septal deviation, which led to a challenging device positioning. After several attempts performed with the patient consent, it was decided to stop treatment. As per protocol, the patient was not replaced. The patient had no evaluable data until the final visit.

\section{Treatment ( $1 \mathrm{~h}$ to $48 \mathrm{~h}$ )}

Two patients had bleeding recurrence. The first one had mild rebleeding at $6 \mathrm{~h}$ which spontaneously stopped at $12 \mathrm{~h}$ without readjusting the volume of air within the balloon. The second patient presented with mild rebleeding at $24 \mathrm{~h}$ for which the balloon was reinflated with $5 \mathrm{~mL}$ of air. This patient suffered from a severe rebleeding at $48 \mathrm{~h}$, which was surgically managed with a sphenopalatine artery ligation.

The volume of air was adjusted for two other patients at $24 \mathrm{~h}$ (one reinflation of $5 \mathrm{~mL}$ and one deflation of $2 \mathrm{~mL}$ ) because of balloon displacement. Overall, the CAVI-T ${ }^{\mathrm{TM}}$ balloon was efficacious to control bleeding in $8 / 10$ patients. 
Table 2. Number and $\%$ of patients per type of adverse events.

\begin{tabular}{|lccl}
\hline \multicolumn{1}{|c|}{ Type of adverse event } & $\begin{array}{c}\text { Patients } \\
\text { with } \\
\text { adverse } \\
\text { events }\end{array}$ & $\begin{array}{c}\text { Device } \\
\text { related }\end{array}$ & Intensity \\
\hline Facial pain & 8 & yes & $\begin{array}{c}\text { mild to } \\
\text { moderate }\end{array}$ \\
\hline Crusting & 4 & yes & mild \\
\hline Recurrence of Epistaxis & 2 & no & mild \\
\hline Clear Rhinorrhea & 2 & yes & mild \\
\hline Maxillary sinusitis & 2 & yes & moderate \\
\hline Anemia & 1 & no & moderate \\
\hline $\begin{array}{l}\text { Device migration / } \\
\text { repositioning }\end{array}$ & 1 & yes & moderate \\
\hline Watery eyes & 1 & yes & mild \\
\hline $\begin{array}{l}\text { Anemia requiring a blood } \\
\text { transfusion }\end{array}$ & 1 & no & severe \\
\hline Headache & 1 & n.d & mild \\
\hline $\begin{array}{l}\text { Epistaxis (requiring } \\
\text { surgical management) }\end{array}$ & 1 & n.d & mild \\
\hline $\begin{array}{l}\text { Spontaneous contralateral } \\
\text { epistaxis }\end{array}$ & 1 & no & severe \\
\hline Labial pain & 1 & yes & mild \\
\hline Fever & 1 & yes & moderate \\
\hline $\begin{array}{l}\text { Pressure ulcer (escar) } \\
\text { Odynophagia }\end{array}$ & 1 & yes & mild \\
\hline Palpebral oedema & 1 & moderate \\
\hline
\end{tabular}

Values given in the table are patients counts ( $n=10)$. ( $n$.d: not determined i.e. causality with the treatment could not be established).

\section{After treatment ( 7 to 10 days post-removal)}

After treatment, two patients reported rebleeding 2 days after balloon removal (one epistaxis recurrence and one spontaneous contralateral epistaxis). The bleeding was self-limited and controlled by the patient in each case.

\section{Safety: pain assessment}

Product positioning (VO)

The pain score was completed by the 10 patients upon balloon placement. Mean [SD] and median score at insertion were respectively 4.7 [4.2] and 6. The VAS scores after balloon inflation were recorded for 9 patients. Mean [SD] and median score at inflation were respectively 6.0 [2.9] and 6 .

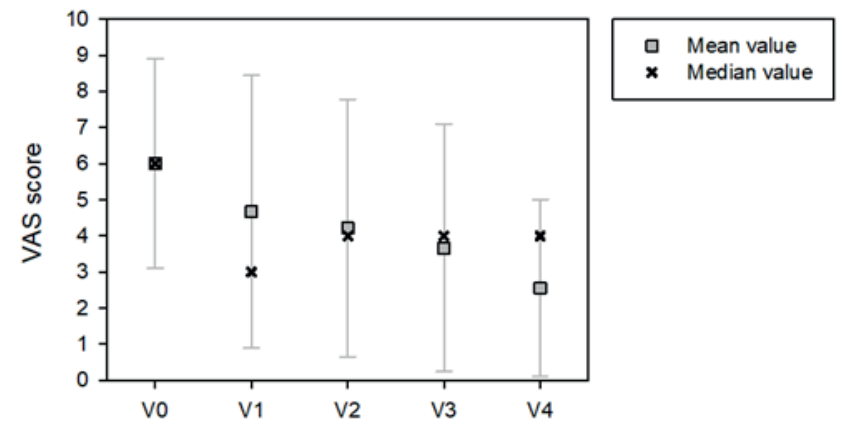

Figure 3. Evolution of the VAS score (mean and median values) at each control visit before removal (from V0 to $24 h$ ) ( $n=9)$.

\section{Treatment ( $1 \mathrm{~h}$ to $48 \mathrm{~h}$ )}

As shown in Figure 3, the mean VAS score [SD] decreases from 6.0 [2.9] at V0 after inflation to 2.6 [2.5] at 24h (V4). The VAS median score reached a plateau of 4 from $6 \mathrm{~h}$ (V2).

The mean $[\mathrm{SD}]$ and median VAS score dropped respectively to 1.6 [1.7] and 1 on removal of the device at 48h (V5).

Deflation of the balloon because of pain was performed for two patients at $6 \mathrm{~h}(2 \mathrm{~mL})$ and one patient at $12 \mathrm{~h}(3 \mathrm{~mL})$ (Additional file 4).

\section{After treatment ( 7 to 10 days post-removal)}

At the last control visit (V6) the mean [SD] VAS score halved (0.8 [1.6]) compared to the value at $48 \mathrm{~h}$ (V5) and the median value dropped to 0 .

\section{Secondary endpoints \\ Safety: adverse events}

Eighteen types of adverse events have been reported (Table 2) for the ten patients. Eight patients (8/10) experienced mild to moderate facial pain, which was the most frequent adverse event, followed by crusting observed endoscopically intranasally after device removal in 4 patients (4/10). Eleven adverse events (68.8\%) of mild to moderate intensity were considered device related. Among those, the most observed were facial pain $(8 / 10)$, crusting $(4 / 10)$, clear rhinorrhea $(2 / 10)$ and maxillary sinusitis (2/10, diagnosed by history and physical examination). Various analgesics (e.g. paracetamol, tramadol, nefopam) were prescribed to nine patients $(9 / 10)$ to treat their pain symptoms. Five patients $(5 / 10)$ recovered without sequelae from the adverse events that they experienced before the end of the study. One patient (1/10) still had maxillary sinusitis and three patients (3/10) still had intranasal crusting (observed endoscopically) at the end of the study. Maxillary sinusitis (clinically assessed based on middle meatus obstruction) was treated with amoxicillin and daily saline lavage. In two patients, crusting did not require any medical management, and one patient was treated with amoxicillin as a preventive measure due to partially obstructive crusts. 

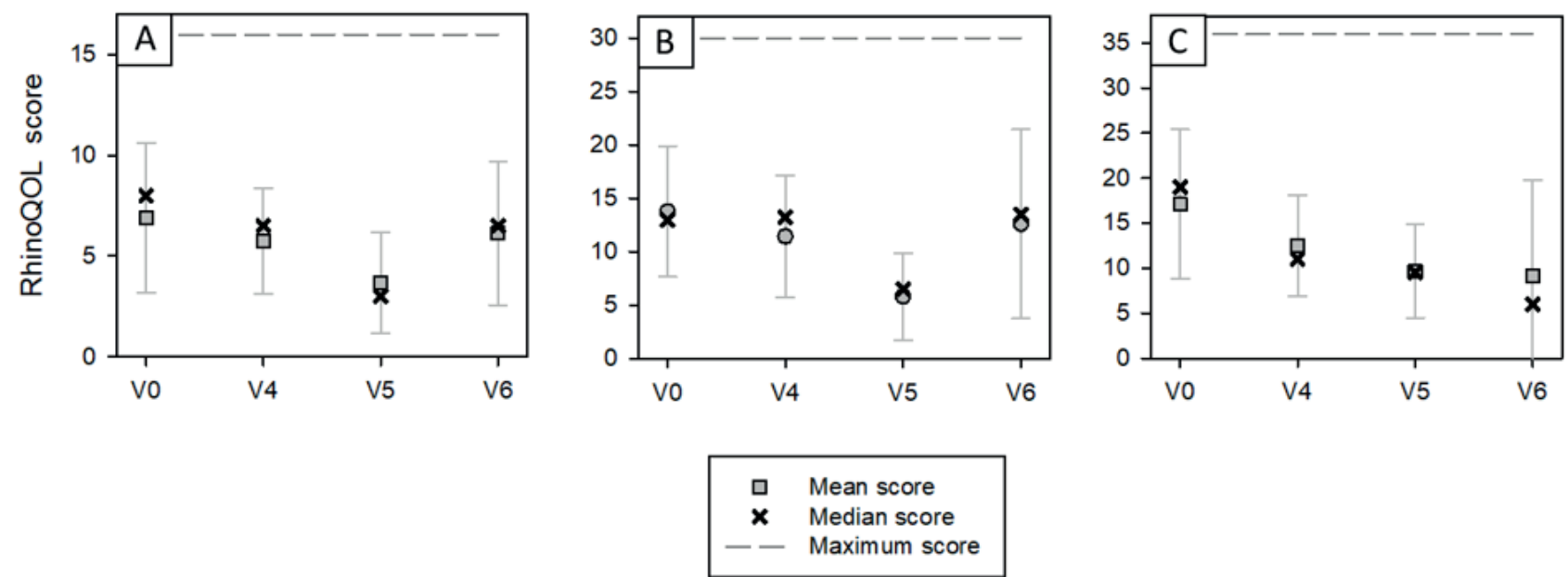

Figure 4. Evolution of the mean and median values of the RhinoQoL scores at V0, 24h(V4),48h (V5) and 7 to 10 days post removal (V6) ( $n=9)$. A. Frequency. B. Bothersomeness. C. Impact.

One patient (1/10) faced two Serious Adverse Events (SAE): anemia (24h) and recurrence of epistaxis (48h). These events were not considered device related. This patient was transfused with two blood units after $24 \mathrm{~h}$ and surgically managed at $72 \mathrm{~h}$ to undergo sphenopalatine artery ligation. Both events were resolved without sequelae.

\section{Quality of life}

When the study was conducted, no specific Quality of Life scale could be identified for spontaneous epistaxis managed in an emergency setting. Therefore, the RhinoQoL questionnaire was used as a proxy to evaluate patient quality of life at V0, $24 \mathrm{~h}$ (V4), 48h (V5) and 7 to 10 days post-removal (V6). The scores obtained for the 9 patients questioned do not exceed two thirds of the limit value (corresponding to the least comfortable state) that can be reached (Figure 4). It is noticeable that the frequency and "bothersomeness" values decrease from V0 to V 5 with V6 values close to the ones obtained at $\mathrm{V} 0$ whereas the impact values continuously diminishes from V0 to V6.

\section{Discussion}

The ideal treatment for epistaxis should 1) be quickly effective to control bleeding, 2) be easy to use, 3) reduce the risk of secondary wounds upon insertion 4) minimize discomfort when in place and allow the patient to breathe through the nose, 5) limit tissue reaction and risk of infection, 6) not damage the mucosal membrane and 7) not trigger rebleeding after removal. Moreover, in an era in which particularly aggressive infections like SARS-COV-2 can occur, solutions that may reduce exposure to blood spatter for healthcare professionals, limit the risk of prolonged hand-to-nose physical contact with patients and relieve hospital physicians from avoidable workloads are required.
This pilot study aimed at demonstrating the acceptable riskbenefit ratio of CAVI-T ${ }^{\mathrm{TM}}$, a new asymmetrical balloon for the treatment of epistaxis. Therefore, given the objective of this first trial, no control group was included. We acknowledge that this pilot study provides limited safety and performance data that will have to be further confirmed.

Performance analysis showed that the balloon was efficacious to stop bleeding immediately after product positioning in $9 / 10$ patients and the efficacy was maintained in $8 / 10$ patients upon treatment. Those results were obtained in a "challenging to treat" elderly population, with a significant medical history, several patients being, in particular, in a hypo-coagulable state and treated with antiplatelets, which are known to promote epistaxis ${ }^{(14)}$. Looking at therapeutic alternatives, a failure rate ranging from 26 to $50 \%$ has been described for tampons ${ }^{(15)}$. Likewise, epistaxis catheters are effective in $62 \%$ of cases with immediate control of bleeding by compression and absence of recurrence upon catheter removal ${ }^{(16)}$.

Hemostasis was obtained with a balloon inflated on average [SD] with $15.9 \mathrm{~mL}$ [4.8] of air (median $=15.0 \mathrm{~mL}$ ) for a maximum recommended of $25 \mathrm{~mL}$, thus leaving 9 to $10 \mathrm{~mL}$ to further titrate in case bleeding would not be adequately controlled or if recurrence occurred. Deflating/re-inflating with CAVI-T ${ }^{\mathrm{TM}}$ was easy to perform, thus allowing fast product repositioning and pressure adjustment.

Safety assessment revealed that the pain score was moderate on the VAS scale at insertion (mean $[\mathrm{SD}]=4.7$ [4.2] and median=6.0), inflation (mean $[S D]=6.0$ [2.9] and median=6.0) and during treatment (2.6 [2.5] $\leq$ mean $[S D] \leq 4.7[3.8] ; 3 \leq$ median $\leq 4)$. These values show promising results with respect to nasal packing 
(tampons) or epistaxis catheters ${ }^{(17,18)}$, although this would have to be confirmed in a larger scale randomized controlled trial. VAS score upon balloon removal and post-removal were mild (mean $[\mathrm{SD}]=1.6$ [1.7] and 0.8 [1.6], median $=1$ and 0 respectively), thus reinforcing the interest of the unique "physiological" design of CAVI-T ${ }^{\mathrm{TM}}$, in particular versus traditional nasal packing (mesh), which can be extremely painful when removed ${ }^{(19)}$. In a study from Moumouloudis et al. ${ }^{(20)}$, pain scores upon removal with Merocel $^{\mathrm{TM}}$ (Medtronic) and Rapid-Rhino ${ }^{\mathrm{TM}}$ (Smith \& Nephew) were, respectively, 5,04 and 2,47. Another study from Bresnihan et al. showed pain scores of respectively 5 and 3.1 with Merocel $^{\mathrm{TM}}$ and Netcell Series $5000^{\mathrm{TM}}$ (Network Medical) tampons ${ }^{(21)}$. 9/10 patients have been treated with analgesics during the study, treatments which may have an impact on the pain score assessed throughout the study. However, prescribing analgesics in such patients is not uncommon ${ }^{(22)}$, thus making comparisons (although indirect) with other studies valid.

The most frequent adverse events considered to be devicerelated were facial pain (8/10), crusting (4/10) clear rhinorrhea $(2 / 10)$ and maxillary sinusitis (2/10). Pain (7/10 at insertion and $3 / 10$ upon treatment) is a common adverse event with products that are used intranasally ${ }^{(19,20)}$. Furthermore, three patients had a septal deviation which could possibly create extra sensitivity upon product insertion.

Crusting is frequent after epistaxis as the coagulation cascade starts and hemostasis is ensured. A study reported crusting in $34 \%$ patients after surgery ${ }^{(23)}$ and another workrelated crusting in 12 to $40 \%$ of patients treated for epistaxis either by cautery, packing or surgery ${ }^{(7)}$. Lastly, rhinorrhea can be explained by the nasal physiopathology. Indeed, the balloon, by filling a large intranasal space, modifies fluid drainage conditions and entails a local stimulation responsible for rhinorrhea. On the whole, device-related complications are common to the ones observed with other intranasal devices ${ }^{(17,24)}$.

One patient presented serious adverse events (anemia and epistaxis recurrence), that were resolved without sequelae. These events have been judged as non-related to the device. Indeed, the patient was suffering from von Willebrand disease and presented a thrombocytosis from undetermined origins.

One patient presented a major septal deviation that hindered the correct positioning of the device and it was decided to stop treatment. As demonstrated by Sireci et al. ${ }^{(25)}$, septal deviation is a potential factor of failure of intranasal packing. Therefore, this patient experience shows that septal deviation can be a potential cause of treatment failure with CAVI-T ${ }^{T M}$ and that patients presenting such an anatomical variation have to be managed with particular attention.

RhinoQoL scores showed a tendency of improvement of quality of life over time. However, a questionnaire more specific to epis- taxis managed in an emergency setting should be developed for more accuracy. This will certainly be the aim of a future work.

The mild VAS score upon balloon removal and the estimation of a potential length of stay of 1.72 [0.68] days on average if patients had been managed outside of the clinical trial are two favorable arguments for a potential use of CAVI-T ${ }^{\mathrm{TM}}$ in an ambulatory setting. Due to its ease of use, the product may also be utilized as a prehospital treatment in order to reduce emergency departments workload. The design of the device, with its stiff $13.5 \mathrm{~cm}$ deployment guide portion, allows to keep enough distance between the patient and the physician during product placement. This feature could thus reduce the risk of exposure to blood spatter for healthcare professionals, as particularly expected in a context like SARS-COV-2 pandemic. Finally, assuming health authorities allow and even promote this practice, CAVI-T ${ }^{\mathrm{TM}}$ might potentially be removed by the patient himself, thus reducing the need for hospital revisits.

In our study, all patients $(\mathrm{n}=10)$ had unilateral bleeding. Given its anatomical design, we can hypothesize that the asymmetric balloon would also be safe and efficacious in a bilateral bleeding scenario, although this would have to be confirmed. In those patients, the breathing channel may represent a key feature compared with nasal tampons, which are obstructive by design. This will have to be formally assessed in upcoming trials.

One particular interest of CAVI-T ${ }^{\mathrm{TM}}$ may reside in its versatility to control bleeding originating from the Kiesselbach plexus and/ or the sphenopalatine artery. Moreover, even though it won't be directly accessible, the device may have a role to play in order to control bleeding from the ethmoidal artery. A study performed on head models is currently underway at the Strasbourg University Hospital to assess whether CAVI-T ${ }^{\mathrm{TM}}$ could be suitable for these types of bleeders.

One limitation of the study is its narrow sample size, which will require to conduct a larger, comparative, multicenter, randomized control trial in order to confirm our initial positive findings.

\section{Conclusions}

Drawbacks of current nasal packing solutions advocates for new methods to treat epistaxis. This pilot study is a first attempt to evaluate the safety and efficacy of an easy to use, patient friendly, asymmetrical balloon, which may adequately complement the therapeutic armamentarium in the management of epistaxis. This product suggests promises as an ambulatory treatment that could potentially be cost saving for the healthcare system. Last, in an era in which particularly aggressive infections like SARS-COV-2 can emerge, the design of the product might present an interest by limiting the risk of prolonged hand-to- 
nose physical contact between healthcare professionals and patients as well as relieve hospital physicians from avoidable workloads. Those first results will have to be confirmed in larger randomized controlled trials.

\section{Acknowledgments}

We gratefully acknowledge the contribution of the patients who participated in this study. We especially acknowledge clinical research sub-investigators for their flawless participation in this trial, as well as the Clinical Research and Innovation Department (DRCl) and the pharmacy team in charge of clinical trials support. Finally, we also warmly thank Dr. Howard L. Levine, MD, for his invaluable assistance as an independent reviewer.

\section{Authorship contribution}

$\mathrm{CD}$ contributed to the design and implementation of the research, to the analysis of the results and to the writing of the manuscript. LN wrote the manuscript with support from CD. LF, GT, ID, PM, NB, PP and SC performed the experiments.

\section{Conflict of interest}

The sponsor (Dianosic) provided funding for the investigation as well as administrative and logistical support. CD is a scientific advisor of the company Dianosic. The authors have no other funding, financial relationships, or conflicts of interest to disclose.

\section{Ethics approval and consent to participate}

Not applicable.

\section{Consent for publication}

Not applicable.

\section{Availability of data and materials Not applicable.}

\section{Funding}

Dianosic was the study sponsor. Administrative fees and Clinical Research Organization tasks were funded by Dianosic. CAVI-T ${ }^{\mathrm{TM}}$ samples were given to the University Hospital of Strasbourg. No other funding was provided.

\section{References}

1. Nikolaou G, Holzmann D, Soyka MB Discomfort and costs in epistaxis treatment. Eur Arch Otorhinolaryngol 2013; 270: 22392244

2. Pope LER, Hobbs CGL. Epistaxis: an update on current management. Postgrad Med 2005; 81: 309-314.

3. Timsit CA, Bouchene K, Olfatpour B, Herman P, Tran Ba Huy P. Epidemiology and clinical findings in 20,563 patients attending the Lariboisière Hospital ENT Adult Emergency Clinic. Ann Otolaryngol Chir Cervicofac 2001; 118: 215-224.

4. Bal dit Sollier C, Drouet L. Epistaxis et traitements antithrombotiques. Sang Thromb Vaiss 2014; 26: 109-121.

5. Mehta N, Stevens K, Smith ME, Williams RJ, Ellis M, Hardman JC, et al. National prospective observational study of inpatient management of adults with epistaxis - a National Trainee Research Collaborative delivered investigation. Rhinology. 2019; 57(3):180-189.

6. Swords C, Patel A, Smith ME, Williams RJ, Kuhn I, Hopkins C. Surgical and interventional radiological management of adult epistaxis:systematic review. J Laryngol Otol 2017; 131: 1108-1130

7. Kindler RM, Holzmann D, Landis BN, Ditzen $B$, Soyka MB. The high rate of long-term recurrences and sequelae after epistaxis treatment. Auris Nasus Larynx 2016; 43: 412-417.

8. Vermeeren L, Derks W, Fokkens W, Menger D-J. Complications of balloon packing in epistaxis. Eur Arch Otorhinolaryngol 2015; 272: 3077-3081.

9. Van Wyk FC, Massey S, Worley G, Brady S. Do all epistaxis patients with a nasal pack need admission? A retrospective study of 116 patients managed in accident and emergency according to a peer reviewed protocol. J Laryngol Otol 2007; 121 :222-227.

10. Coey JG, Whittaker PJ, Williams G, Ikram UH, Page OJR. Fibrin tissue adhesive versus nasal packing in endoscopic nasal surgery: a systematic review and meta-analysis. Rhinology. 2019; 57(1): 21-31.

11. Marro M, Mondina M, Stoll D, de Gabory $L$. French validation of the NOSE and RhinoQoL questionnaires in the management of nasal obstruction. Otolaryngo Head Neck Surg 2011; 144(6): 988-993.

12. Atlas SJ, Gallagher PM, Wu YA et al. Development and validation of a new health-related quality of life instrument for patients with sinusitis. Qual Life Res 2005;14: 1375-1386.

13. Atlas SJ, Metson RB, Singer DE, Wu YA Gliklich RE. Validity of a new health-related quality of life instrument for patients with chronic sinusitis. Laryngoscope 2005; 115 : 846-854.

14. Beck R, Sorge M, Schneider A, Dietz A: Current approaches to epistaxis treatment in primary and secondary care. Dtsch Arztebl Int 2018; 115: 12-22

15. Schaitkin B, Strauss M, Houck JR. Epistaxis: medical versus surgical therapy: a comparison of efficacy, complications, and economic considerations. Laryngoscope 1987; 97: 1392-1395.

16. Klotz DA, Winkle MR, Richmon J, Hengerer Arthur S. Surgical Management of Posterior Epistaxis: A Changing Paradigm. Laryngoscope 2002; 112(9): 1577-1582.

17. Zou Y, Deng YQ, Xiao CW, Kong YG, Xu Y,
Tao ZZ, Shen SM. Comparison of outcomes between endoscopic surgery and conventional nasal packing for epistaxis in the posterior fornix of the inferior nasal meatus. Pak J Med Sci 2015; 31(6): 1361-1365.

18. Kahn MA, Sumera A, Attique A, Bhatti A. To compare efficacy and discomfort in posterior nasal packing with Foley's catheters versus Bipp gauze in cases of posterior epistaxis. Armed Forces Med J 2015; 65(5): 640-643.

19. Bachelet JT, Bourlet J, Gleizal A. Hemostatic absorbable gel matrix for severe posttraumatic epistaxis. Rev Stomatol Chir Maxillofac Chir Orale 2013; 114(5): 310-314.

20. Moumoulidis I, Draper, MR, Patel H, Jani $\mathrm{P}$, Price T. A prospective randomised controlled trial comparing Merocel and Rapid Rhino nasal tampons in the treatment of epistaxis. Eur Arch Otorhinolaryngol 2006; 263(8): 719-722.

21. Bresnihan M, Mehigan B, Curran A. An evaluation of Merocel and Series 5000 nasal packs in patients following nasal surgery: a prospective randomised trial. Clin Otolaryngol 2007; 32(5): 352-355

22. Crampette L, Herman P, Malard O. Epistaxis. Rapport de la Société Française d'ORL et de chirurgie Cervico-Faciale. 2015:1-177

23. Snyderman $\mathrm{CH}$, Goldman SA, Carrau RL et al. Endoscopic sphenopalatine artery ligation is an effective method of treatment for posterior epistaxis. Am J Rhinol 1999; 13:137-140

24. Wang L, Vogel DH, Posterior epistaxis: comparison of treatment. Otolaryngol Head Neck Surg 1981; 89: 1001-1006.

25. Sireci F, Speciale R, Sorrentino R, TurriZanoni M, Nicolotti M, Canevari FR. Nasal packing in sphenopalatine artery bleed- 
ing: therapeutic or harmful? Eur Arch Otorhinolaryngol 2017; 274: 1501-1505.

\section{Prof C. Debry}

Hôpitaux Universitaires de Strasbourg Service de chirurgie ORL et cervico-

-faciale

Hôpital Hautepierre

1 avenue Molière

67098 Strasbourg

Fance

Tel: +33-88-12-7644

Fax: +33-88-12-8289

E-mail:

christian.debry@chru-strasbourg.fr

ISSN: 2589-5613 / @2020 The Author(s). This work is licensed under a Creative Commons Attribution 4.0 International License. The images or other third party material in this article are included in the article's Creative Commons license, unless indicated otherwise in the credit line; if the material is not included under the Creative Commons license, users will need to obtain permission from the license holder to reproduce the material. To view a copy of this license, visit http://creativecommons.org/ licenses/by/4.0/ 


\section{SUPPLEMENTARY INFORMATION}

Additional file 1. Sagittal cross-section showing the deployment of CAVI$\mathrm{T}^{\mathrm{TM}}$ within the intranasal cavity of an adult human head model. (inflation with $15 \mathrm{~mL}$ of a solution composed of IOMERON 300 (300 mg lode/mL) and physiological saline ( $\mathrm{NaCL} 0.9 \%$ ) in a $1 / 6$ volume ratio. Note: this figure is given as an example. Product positioning may vary and be adapted depending on the bleeding site.

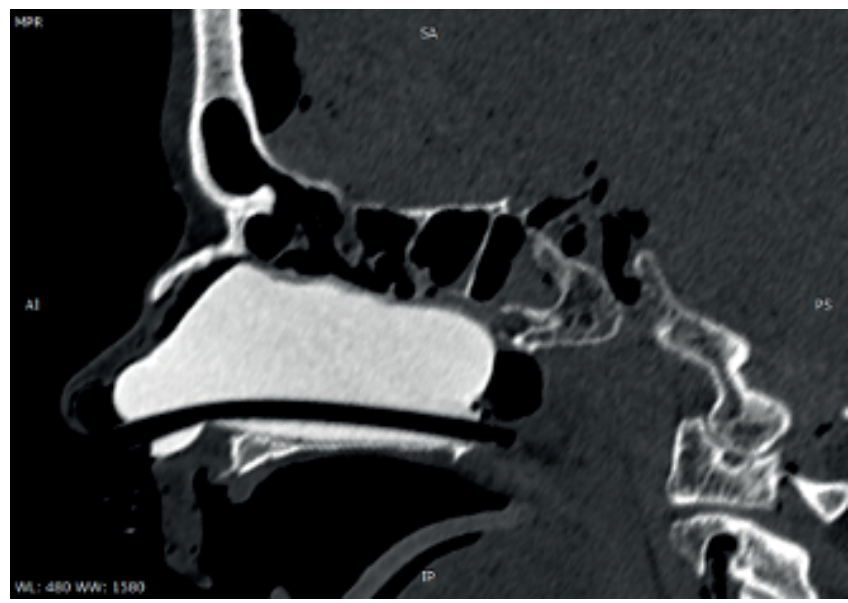

Additional file 2. Information gathered and examinations performed at each visit during the study. (a) with a nasal speculum and endoscopic exam by flexible fiberoptic endoscope to assess potential complications (bleeding persistence, healing defect, mucosal or cutaneous necrosis); (b) control of hemoglobin, hematocrit levels and hemostasis prior to potential transfusion ; * examinations routinely performed in epistaxis management (outside of this feasibility study).

\begin{tabular}{|c|c|c|c|c|c|c|c|c|}
\hline VISITS & $\begin{array}{c}\text { Vo } \\
\text { Informa- } \\
\text { tion/Inclu- } \\
\text { sion }\end{array}$ & $\begin{array}{l}\text { V1 } \\
\text { (1h) }\end{array}$ & $\begin{array}{l}\text { V2 } \\
(6 h)\end{array}$ & $\begin{array}{l}\text { V3 } \\
(12 h)\end{array}$ & $\begin{array}{l}\text { V4 } \\
(24 h)\end{array}$ & $\begin{array}{c}\text { V5 } \\
\text { (48h) } \\
\text { Device } \\
\text { removal }\end{array}$ & $\begin{array}{c}\text { V6 } \\
\text { (7 to } 10 \\
\text { days) Clos- } \\
\text { ing visit }\end{array}$ & $\begin{array}{l}\text { Premature } \\
\text { exit visit }\end{array}$ \\
\hline Type of visit & $\begin{array}{l}\text { Emergency } \\
\text { consultation }\end{array}$ & $\begin{array}{l}\text { Program- } \\
\text { med } \\
\text { consultation }\end{array}$ & $\begin{array}{l}\text { Program- } \\
\text { med } \\
\text { consultation }\end{array}$ & $\begin{array}{l}\text { Program- } \\
\text { med c } \\
\text { onsultation }\end{array}$ & $\begin{array}{l}\text { Program- } \\
\text { med } \\
\text { consultation }\end{array}$ & $\begin{array}{l}\text { Program- } \\
\text { med } \\
\text { consultation }\end{array}$ & $\begin{array}{l}\text { Program- } \\
\text { med } \\
\text { consultation }\end{array}$ & $\begin{array}{l}\text { Non-pro- } \\
\text { grammed } \\
\text { consultation }\end{array}$ \\
\hline Demographics & $X^{*}$ & & & & & & & \\
\hline Medical/surgical history & $X^{*}$ & & & & & & & \\
\hline $\begin{array}{l}\text { Control of the eligibility } \\
\text { criteria }\end{array}$ & $x$ & & & & & & & \\
\hline $\begin{array}{l}\text { Signature of the } \\
\text { informed consent }\end{array}$ & $x$ & & & & & & & \\
\hline $\begin{array}{l}\text { Introduction of the } \\
\text { balloon }\end{array}$ & $x$ & & & & & & & \\
\hline $\begin{array}{l}\text { Assessment of anterior } \\
\text { and posterior bleeding } \\
\text { cessation }\end{array}$ & $x$ & $x$ & $x$ & $x$ & $x$ & $x$ & & \\
\hline RhinoQol questionnaire & $x$ & & & & $x$ & $x$ & $x$ & \\
\hline Evaluation of pain (VAS) & $x$ & $x$ & $x$ & $x$ & $x$ & $x$ & $x$ & \\
\hline Clinical examination ${ }^{a}$ & & & & & & $x$ & $x$ & $x$ \\
\hline Biological analyses ${ }^{b}$ & $X^{*}$ & & & & & & $X^{*}$ & \\
\hline $\begin{array}{l}\text { Undesirable events } \\
\text { collection }\end{array}$ & $x$ & $x$ & $x$ & $x$ & $x$ & $x$ & $x$ & $x$ \\
\hline $\begin{array}{l}\text { Concomitant treatments } \\
\text { collection }\end{array}$ & $x$ & $x$ & $x$ & $x$ & $x$ & $x$ & $x$ & $x$ \\
\hline
\end{tabular}


Additional file 3. Volume of air injected in the balloon at positioning and volume of air present in the balloon after immediate adjustment for the different patients enrolled in the study.
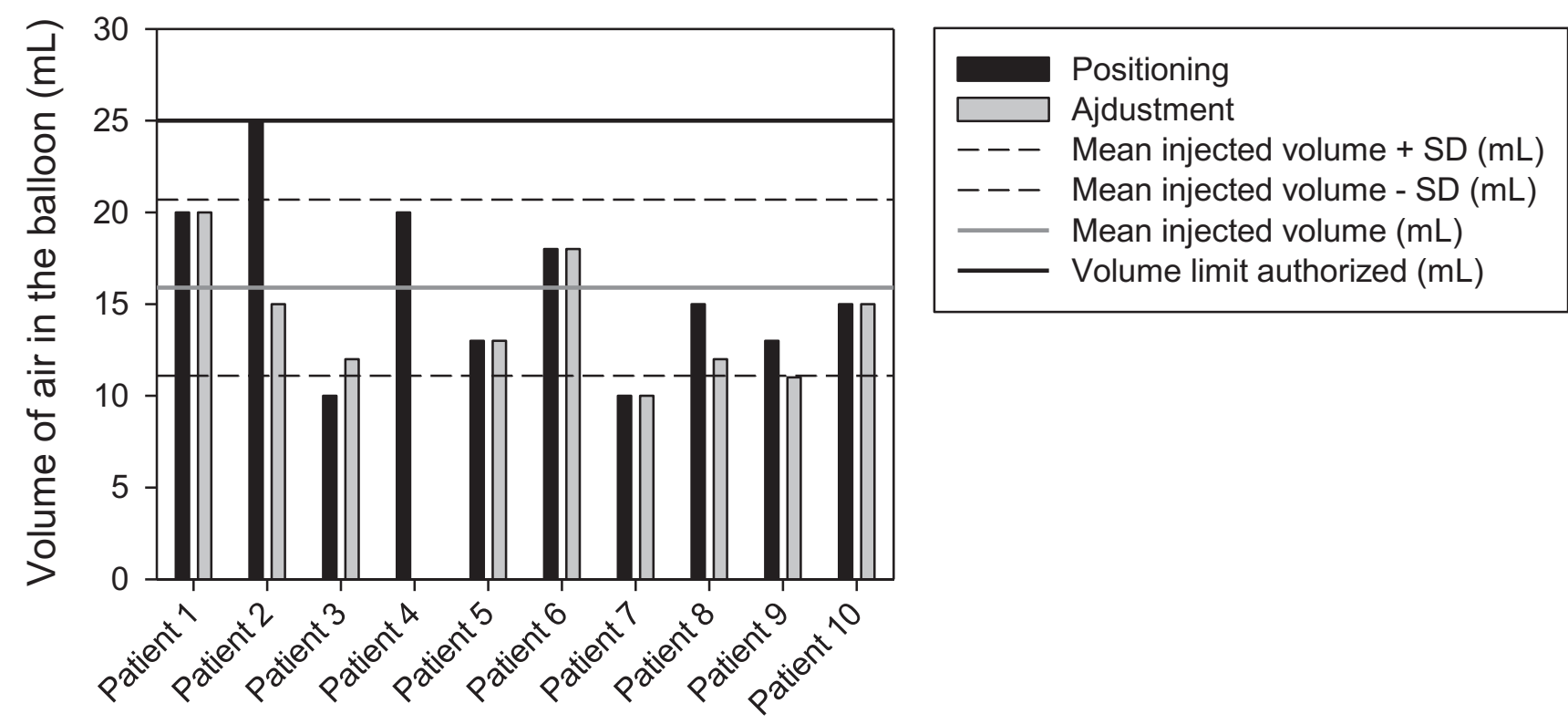

Additional file 4. Evolution of the volume of air in the balloon at each visit (volumes were assessed and/or modified only during the control visits). Since V5 corresponds to the time of device removal, values are not reported here.

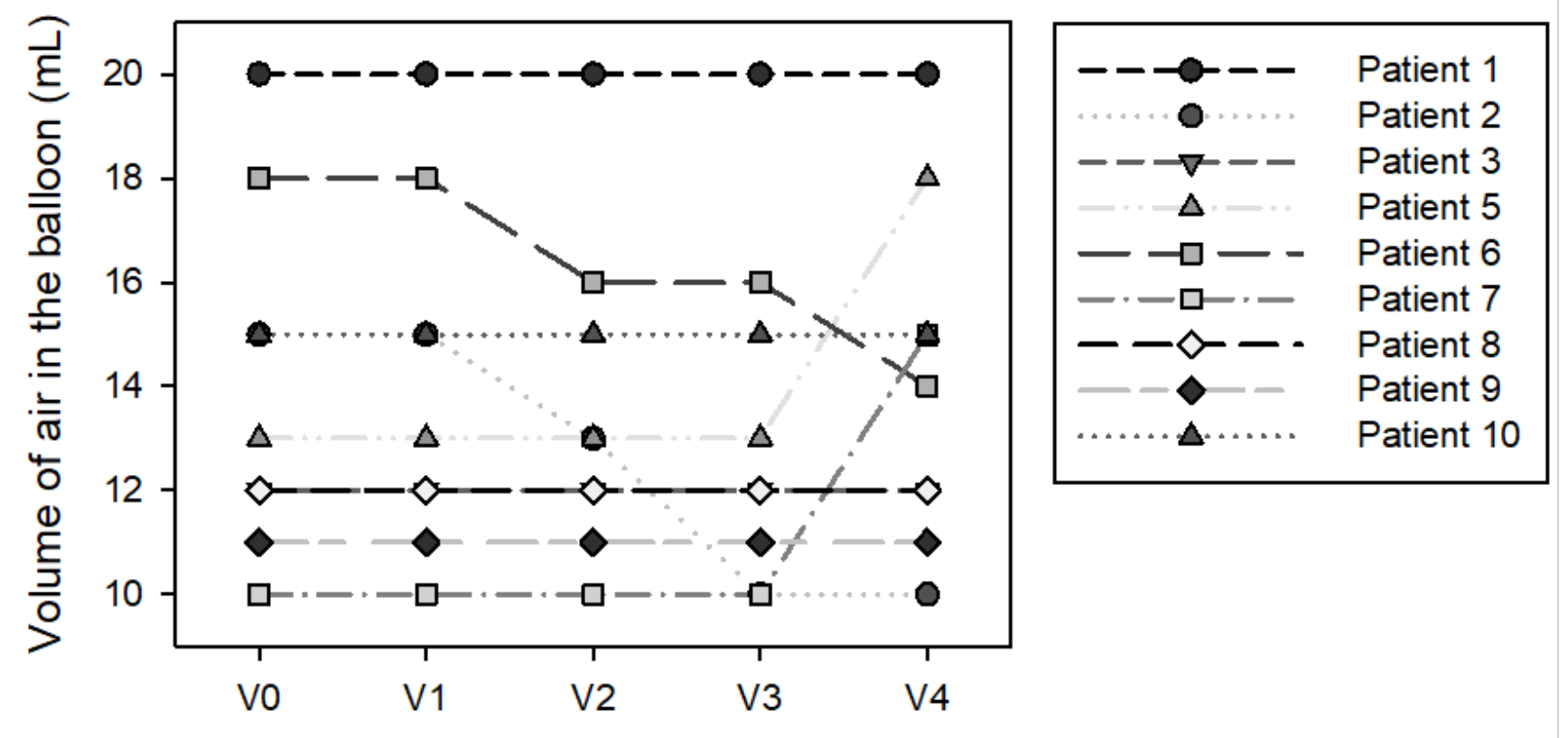

